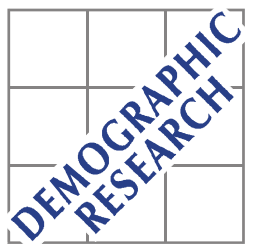

Demographic Research a free, expedited, online journal of peer-reviewed research and commentary in the population sciences published by the Max Planck Institute for Demographic Research Konrad-Zuse Str. 1, D-18057 Rostock · GERMANY www.demographic-research.org

DEMOGRAPHIC RESEARCH

VOLUME 22, ARTICLE 22, PAGES 663-690 PUBLISHED 20 APRIL 2010

http://www.demographic-research.org/Volumes/Vol22/22/

DOI: $10.4054 /$ DemRes.2010.22.22

Reflexion

\title{
Demographers' interest in fertility trends and determinants in developed countries: Is it warranted?
}

\section{Øystein Kravdal}

(C) 2010 Øystein Kravdal.

This open-access work is published under the terms of the Creative Commons Attribution NonCommercial License 2.0 Germany, which permits use, reproduction \& distribution in any medium for non-commercial purposes, provided the original author(s) and source are given credit.

See http:// creativecommons.org/licenses/by-nc/2.0/de/ 


\section{Table of Contents}

1 Introduction $\quad 664$

2 Individual-level consequences of low fertility 665

$2.1 \quad$ Possible effects of childbearing on parents' lives 665

2.2 Possible effects of siblings on children's lives 667

2.3 Identification problems 668

$2.4 \quad$ Society's response to individual-level effects 669

$2.5 \quad$ Unsatisfied desires - reason for concern? 671

$3 \quad$ Societal-level consequences of low fertility 672

$3.1 \quad$ Possible macro-level effects of low fertility 672

3.2 Should anything be done to increase fertility? 675

3.3 Other responses to possible societal-level consequences 677

3.4 Another perspective: Low fertility is unproblematic, but we need to 679 know about it

$\begin{array}{lll}4 & \text { Conclusions } & 680\end{array}$

5 Acknowledgements $\quad 681$

$\begin{array}{ll}\text { References } & 682\end{array}$

$\begin{array}{ll}\text { Appendix } & 690\end{array}$ 


\title{
Demographers' interest in fertility trends and determinants in developed countries: Is it warranted?
}

\author{
Øystein Kravdal ${ }^{1}$
}

\begin{abstract}
Studies of fertility trends and determinants in developed countries are high on demographers' research agenda. The interest in this subject is probably, to a large extent, motivated by a notion about low fertility being problematic, but demographers have not been much engaged in efforts to find out whether that is actually the case, at least as judged from the contents of the major demography journals. In this paper, the possibility of various individual- and societal-level effects of low fertility is briefly reviewed. Some of the harmful effects may be foreseen and considered an acceptable disadvantage by couples making fertility decisions, while others more rightly can be considered social problems. It is argued that knowledge about fertility trends and determinants may help us learn more about the consequences of low fertility and see clearer whether interventions may be justified and what specific steps one might take. Further efforts to expand this knowledge should therefore be welcome, and it is possible that demographers can make an important contribution by applying this knowledge in studies of consequences of fertility. A higher priority to forecasting might also be worthwhile.
\end{abstract}

\footnotetext{
${ }^{1}$ Department of Economics, University of Oslo and Statistics Norway. E-mail: oystein.kravdal@econ.uio.no.
} 


\section{Introduction}

Several studies of fertility in developed countries are published every year, in journals, books, and various types of reports. However, as judged from the contents of the major demography journals over the last couple of decades, researchers who reckon themselves as demographers are primarily interested in describing fertility patterns or assessing how various individual or societal factors affect fertility. The possible consequences of low fertility have attracted much less attention in these outlets (see Appendix Table A1 for some statistics). ${ }^{2}$ This may be considered as reflecting a general research tradition in demography. For many years, demographers seem to have been more interested in the determinants of demographic behaviour than in the consequences, unless the consequences are also "demographic" of course. Particularly, little attention has been paid to the welfare consequences at the micro level (Hobcraft 2006).

It is not obvious what the motivation for the quite massive efforts to analyse fertility trends and determinants in low-fertility settings actually is. While the authors of such papers of course explain the importance of the specific questions they address, the more fundamental motivation is usually not spelled out. Presumably, many researchers are driven by a somewhat diffuse idea that low fertility is potentially problematic for society or individual families and that it therefore may somehow be useful to know much about the trends and patterns in fertility and its determinants. ${ }^{3}$ At least, some papers hint at such a rationale.

In this paper, I discuss the potential value of research on trends and determinants of fertility in low-fertility settings. When doing this, I take for granted that the main goal of social science research in general is to establish knowledge that somehow (directly or by facilitating other research efforts) can improve the quality of life by helping individuals, politicians and planners in making wise decisions. In other words, the key question is whether and how knowledge about fertility trends and determinants

\footnotetext{
${ }^{2}$ It should be noted, though, that it is often difficult to draw a sharp dividing line between analysis of consequences and analysis of determinants. One important reason is that a factor may affect fertility because it influences the implications of childbearing. For example, the fertility-depressing effect of education is probably partly the result of educational differences in the opportunity costs of childbearing. Thus, a few lines about consequences of fertility may be necessary to include in an analysis otherwise primarily dealing with determinants.

${ }^{3}$ Another and probably much less widespread justification for such research may be that it provides us with information about the characteristics of the parents of the next generation (Musick and Mare 2004). For example, if better-educated women and men have fewer children than the less educated (Kravdal and Rindfuss 2008), there will be a relatively small proportion in the next generation having better-educated parents. That is not necessarily something to be worried about, and that could warrant attempts to stimulate fertility in this group in particular (such as authorities in Singapore have tried; Palen 1986), but one might think that it could somehow be helpful to at least know the situation.
} 
may contribute positively in this way. It is of course not sufficient that knowledge is established by researchers. To be influential it must also be disseminated to potential users. However, while it may well be worth discussing how this dissemination should be done and who should be involved, such issues are not dealt with in this paper.

More specifically, this paper has two main parts, one about individual-level consequences and one about societal-level consequences. Each part starts with a brief review of the type of effects that low fertility may have, and I make the point that knowledge about trends and determinants may help us learn more about these effects. Next, I discuss whether the various consequences of low fertility may justify some sort of action, by politicians or others, what kind of steps one in principle might take, whether knowledge about fertility trends and determinants may help us answer such questions, and whether such knowledge also may be valuable after it has been decided how to respond to the potential problems associated with low-fertility. Such an attempt to clarify the research motivation may be important to investigators who need to see a deeper value of their efforts in order to keep up the work spirit, and it is certainly important to the agencies that fund this type of research, and that typically have an eye to the "usefulness" of the scholarly activities.

My focus is on completed fertility. The age at first birth influences the number of children people eventually have, and it may have individual- and societal-level effects beyond that (Mirowski 2005, Lutz and Skirbekk 2005), but such issues are ignored. Further, the attention is largely devoted to intended fertility. Issues related to physiological constraints on fertility and unwanted births are not addressed specifically. The discussion is primarily meant to be relevant for wealthy countries, but most of it is relevant also for poor countries that experience low birth rates, such as China (Zhang and Zhao 2006).

\section{Individual-level consequences of low fertility}

\subsection{Possible effects of childbearing on parents' lives}

Childbearing affects people's welfare and lifestyle in a number of ways. Some of these effects may be foreseen by the parents themselves and perhaps be desired. For example, children provide the parents with certain emotional pleasures, which of course is one reason why they want to have children. More specifically, children may show affection, they may help their parents feel that life has a purpose, they may be seen as giving the parents adult status (relevant only for the youngest parents), it may be fun for the parents to engage in various activities with the children, and it may be exciting to see them develop (Hoffman and Manis 1979; Nauck and Klaus 2007). 
Childbearing also has economic implications, and the potential economic rewards have traditionally been - and still are in poor countries - a central motive for having children (Caldwell 1976). More importantly from the perspective of this paper, there are many children also in contemporary developed countries that contribute to the family income through agricultural or other types of work (Council of Europe 1996). Further, financial support from adult children may be important to the poorest segments of the elderly population in these countries, especially where public support systems are not well developed (Rendall and Bahchieva 1998). Children may of course also provide practical assistance when the parents are old or sick or are under special pressure for other reasons (Antonucchi et al. 2003; Barefoot et al. 2005; Lusyne and Page 2008). One may speculate whether such financial or practical help from children may become more important in the future because of an ageing-induced (see discussion below) strain on the public support arrangements

However, there is also a negative side, in the sense that there are large expenses involved. A child needs, for example, food, clothes and equipment for leisure activities, and the parents will either have to forego some income because one of them (typically the mother) must withdraw from the labour force to care for the child the first years (Joshi 2002, OECD 2002), or they must pay others to do the child care. One or both parents may be able to put in extra hours of gainful work to ease the situation, but the family may still end up with a relatively weak economy (Aassve et al. 2006). It should also be noted that withdrawal from the labour market may be a loss not only economically, but also because of the social and other pleasures one may enjoy at the work place (perhaps not fully matched by the pleasures of spending more time with the child), and because a smaller economic contribution may weaken the woman's influence vis-à-vis her partner more generally (England and Folbre 2005).

Childrearing probably also has other types of effects - expected or unexpected by the parents. For example, parents may be less inclined to take risks than the childless (Wang et al. 2009), they may be subject to stronger social control at home (Kendig et al. 2007), and they may be better socially integrated into the community (Knoster and Eggebeen 2006; Bühler 2008). Less favourably, they may also be more inclined to suffer from stress because of worries (beyond the economic ones alluded to above) and too many obligations (Evenson and Simon 2005; Mastekaasa 2000). Besides, the quality of the relationship may be influenced by whether the couple have children, how many they have, and the children's age. On the one hand, it is a common notion that being able to share the pleasures of child rearing and seeing the child develop in a positive way may strengthen a relationship (Hoffman and Manis 1982). On the other hand, less time for work, (joint) leisure activities and intimacy with each other, more routine household tasks, and worries about the children may have the opposite effect, perhaps especially if the burdens are not equally shared. A number of studies have 
shown that the latter effects dominate so that marital satisfaction declines after a child is born or even with each additional child (Twenge et al. 2003). However, many couples with a quite poor relationship may decide to stay together because they think (rightly or not) that this is best for the child, so the association between fertility and the disruption rate (also reflecting selection of course) is generally negative: women and men with many (young) children are less likely to divorce than those with fewer children (Andersson 1997).

Many of these consequences of childbearing may in turn influence the parents' health and mortality (Grundy and Kravdal 2008). In addition, there may be physiological effects. Most importantly in developed countries, pregnancies may affect the mother's chance of developing cancer (in either direction, but most commonly in a favourable one) through hormonal changes or other physiological mechanisms (Salehi et al, 2008; Russo and Russo 2007). There may also be biological effects on the chance of getting other diseases (Fletcher et al. 2002; Skilton et al. 2009). Obviously, such effects of parenthood are not relevant for men.

\subsection{Possible effects of siblings on children's lives}

It is widely believed that children may benefit from having siblings, and this notion may be a factor behind the two-child norm that probably has affected fertility in wealthy countries for a long time (Blake 1968). However, there are likely to be both disadvantages and advantages, and there is little knowledge about the total impact. To start with the latter, several (but not all) studies have shown that children with siblings have particularly well developed social skills (e.g. Downey and Condron 2004). They may also tend to be less involved in activities that one can do alone and that may have some negative implications, such as watching TV (e.g. Bagley et al. 2006). On the other hand, there may be less economic resources available to those who have (several) siblings, both in childhood and later (Keister 2003), and they may get less attention from the parents. Because of such or other mechanisms, one might expect them to end up with less education, which has indeed also been shown in some studies (Polit and Falbo 1988; Downey 1995). By and large, however, there is no consistent empirical support for such an effect on educational achievements. For example, in a recent Norwegian investigation based on a large register-based data material, it was shown that the educational level attained by a first child does not depend on whether he or she has younger siblings (but that the younger siblings end up with less education than the first-born) (Black et al. 2005). Presumably, the effects of having siblings depend on the 
economic resources of the parents and in society, and whether the parents have wanted as many children as they have. Such interactions have not attracted much attention. ${ }^{4}$

Some studies have also documented an intergenerational transmission of low fertility (Murphy and Knudsen 2002): those who have few siblings also tend to have few children themselves. Thus, if it is a disadvantage to have few children, there is an additional burden for those with few siblings.

\subsection{Identification problems}

Unfortunately, it is difficult to statistically identify such individual-level effects of childbearing on parents' and children's well-being, since there are many potential confounders. The desire to have a child depends, for example, on the partners' earning potentials (Becker 1991), the quality of their relationship (Rijken and Liefbroer 2009), their access to child care (Rindfuss et al. 2007), their health (Testa 2007), and their preferences (i.e. whether, given incomes and childbearing costs, they want to spend time and money on children rather than other sources of satisfaction), which in turn depend on such factors as for example how urban their place of residence is (Kulu et al. 2007) and their broader set of values (Lesthaeghe and Surkyn 1988). In addition, fertility is not only determined by the desire for another child, but also by whether it is physiologically possible to bear a child and the availability of contraceptives, which in turn are influenced by a number of factors (Easterlin and Crimmins 1985). Many of these fertility determinants may also affect, for example, the parents' later health or the children's development, but it is in practice difficult to fully control for them in a statistical analysis.

It is hard to believe that one can ever make experiments in order to learn more about the individual-level causal effects of low fertility, but it may be possible to squeeze some information out of the differentials between those with single births and those with a twin birth, which may be considered a natural experiment ( $\mathrm{Li}$ et al. 2008). The sex composition of the children is also an exogenous factor that may used for identification (Angrist and Evans 1998), because it affects the chance of having additional children but perhaps not the outcome under study more directly. The use of more advanced simultaneous-equation modelling (one set of equations for births and another for child outcomes) that allows control for joint unobserved confounders may

\footnotetext{
${ }^{4}$ In developing countries, it is often found that children with many siblings have a disadvantage both with respect to education and many other outcomes (e.g. Li et al. 2008). This disadvantage is now one of the most widely accepted motives for the efforts to reduce fertility, preferably through initiatives to avoid unwanted births, while the societal problems related to high population growth have been downplayed. See e.g. McIntosh and Finkle (1995) or Cleland et al. (2006).
} 
also be helpful (Steele et al. 2009). However, the most promising avenue is perhaps to collect panel data that include very rich information about various relevant welfare indicators of interest as well as what the individuals think about having (more) children. Because of their knowledge about determinants of fertility, demographers may have an important role to play in the construction and analysis of such data - regardless of whether the outcome under study is another "demographic event", such as divorce or death, or something else.

\subsection{Society's response to individual-level effects}

To the extent that low fertility really has effects at the individual level, is there any reason for concern? What kind of interventions might be appropriate, and how can demographers help? To facilitate the discussion of this, let us consider only one specific example: the consequences of wanting and having a second child versus remaining onechild parents.

It seems reasonable to assume that parents take both their own well-being and that of their children into account when making decisions. The situation is particularly simple if it is expected that both parties will benefit from, say, a decision to remain onechild parents. Surely, the parents may see disadvantages of not having another child, such as the possibility of getting relatively little support when they are older, but they may think that this is more than outweighed by the advantage of having few children to care for while they are young adults. They may also be aware of the possible problems related to the socialization of an only child, but they may think that there are also advantages in terms of, say, more economic resources per child, so that the total effect on the child is likely to be non-negative. With this win-win situation the decision to have no more children is obviously sound. Stated differently, there are certain negative consequences both for the parents and the child, but they are outweighed by advantages for both parties, so a wise decision has been made. There is no "problem", in the sense that others perhaps should have intervened to help the parents make another decision.

Alternatively, the parents may realize that being an only child, by and large, is a disadvantage, but that it is small compared to what they gain themselves from having only one child. In principle, the opposite could also be possible. In either case, there is a conflict of interest and some bad outcomes that it might be helpful for politicians and planners to be aware of, but it is not obvious that the parents make a wrong decision by having no more children. If, on the other hand, the expected disadvantage for one of the parties is larger than the expected advantage for the other, it would be unreasonable to have only one child. Presumably, the parents do not make such a decision. 
A quite different issue is that parents may be unaware of the consequences of their decision. This point was addressed also by Kohler et al. (2005), who argued that the relatively low level of happiness in the short term among two-child mothers could be partly due to underestimation of the additional work implied by a second child. Alternatively, it may turn out when the parents are older and need assistance from others that it is much more problematic than they thought to have only one child, or that it is more problematic than foreseen to be an only child. This situation must, of course, be general to deserve attention. There will always be some people who experience more negative outcomes than expected, while it may be opposite for others. The key issue from the perspective of this paper is whether childbearing tends to have more negative socio-economic, emotional or physiological consequences than the parents have foreseen and taken into account.

If future research reveals that that there are such negative consequences of low fertility that parents tend not to take into account, knowledge about these consequences must be disseminated so that people can act in their own interest. This includes any new findings about individual-level consequences of childbearing, as well as knowledge that is already well established but unknown to many parents. However, to avoid spending any resources on finding out what parents know and don't know, the conclusion must be that one should communicate widely everything that is known about the consequences. Redundant information can hardly be a problem.

This argumentation hinges on the assumption that dissemination of knowledge is inexpensive compared to the welfare losses resulting from the "wrong" decisions that would otherwise be made, which seems reasonable in a developed-country setting. It should also be noted that knowledge not necessarily leads to the change in reasonable behaviour. Many people may know what is best for them in the long run (after taking into account the value of current compared to later pleasure, as they see it) without really taking it to heart and act accordingly. This issue is addressed, for example, in the literature on smoking and drug abuse (Elster and Skog 1999), but not further dealt with here.

To summarize, there is reason for concern, particularly if low fertility has consequences for adults or children that parents are not aware of. A sound response would be to disseminate existing knowledge about all individual-level consequences of low fertility and make efforts to learn more. Knowledge about fertility trends and determinants, whether produced by demographers or others, can facilitate such further identification of fertility effects. In principle, one might try to find out what is already known to the parents and only spread information about the remaining consequences (and if parents so far are well informed, there would not even be a "problem", unless there are additional harmful consequences not yet known to anyone), but that would probably not be worthwhile. 


\subsection{Unsatisfied desires - reason for concern?}

There is also another type of individual-level "problem" that occasionally has been discussed, perhaps more in the grey literature and in policy reports (Commission of the European Communities 2006; European Foundation for the Improvement of Living and Working Conditions 2004) than in scholarly journals. The idea is that many people have fewer children than they consider "ideal" or would have liked to have if they were richer or healthier or had better access to child care, and that this is sad for them. (In principle, low fertility may have adverse societal-level effects, so that it would also be better for others if they had more children - for example all the children that they ideally would have liked to have - but that is another issue, which is dealt with below.) However, it is not really obvious that such an individual feeling of discomfort resulting from unsatisfied fertility desires should be considered a "problem" in the sense that other people need to bother. As also pointed out by Lutz (2007), we all have unsatisfied desires. Some people would have taken great pleasure in driving a Rolls Royce, but do not have the money to buy it, while others dream about an annual 8-week vacation. The key issue must be whether the obstacles to further childbearing are "avoidable" or "unreasonable", in the sense that they could be removed without taking too much from others. For example, if there are laws that make it extremely difficult to have a second child, but that have no favourable impact on anything else, they may be abolished. This is far-fetched, however. More realistically, there are economic or practical obstacles that can only be removed at the expense of others' well-being.

To elaborate on this issue, let us assume that a couple's reason for not having another child is that it would cost, say, $€ 150,000$ to raise this child, while the emotional gains they would receive from that would only correspond to various other pleasures they could buy in the market for $€ 100,000$. If the costs were subsidized by $€ 60,000$, the couples might have had a child and been better off, but would that be a reasonable policy (assuming again that there are no externalities of childbearing)? Others would lose a total of $€ 60,000$ that they could have used to increase their wellbeing. In fact, their income loss is even larger than the benefit for the childbearing couple. Alternatively, assume that the price of a second child is $€ 90,000$, so that the couple might have one if they had the money, but that the amount is out of reach. Should we increase the couple's income by taking from others, who might have bought something else for that amount that is just as valuable to them?

In contrast, it might be acceptable to provide outside assistance if the child is worth much more than the price, for example if it is worth $€ 1$ million while the price is $€ 150,000$. Others would suffer a corresponding loss of income, but they may not be 
able to get as much for their money. However, this may not be a very realistic scenario. ${ }^{5}$ Anyway, it would of course be very difficult in practice to document that an increase in total utility may be achieved, and especially when one must compare different types of utility (the value of having another child versus the value of what others might have bought for the amount of support).

\section{Societal-level consequences of low fertility}

\subsection{Possible macro-level effects of low fertility}

Most developed countries ${ }^{6}$ will experience considerable ageing over the next decades regardless of the level of fertility in the years to come, but low fertility exacerbates the ageing, and it will also reduce the growth of the population size and perhaps even lead to a decline. ${ }^{7}$

There is a large literature on the consequences of ageing, not least within economic research. One strand of this literature essentially deals with the economic consequences of increasing old-age dependency ratios. For example, it has been argued that it may be difficult to sustain the commonly used pay-as-you-go pension system in a population with a larger proportion of elderly (Blake and Mayhew 2006). One may have to reduce the pensions, tax the workers heavier, or take up loans abroad, with possibly increased dependence on other countries. In addition, a higher proportion of elderly, who are the largest consumers of health services, will contribute to higher health expenditures (Dormont et al. 2006). Again, the result may be lower quality of the medical care (which is not to the same extent as the pensions regulated by law), or higher taxes or fiscal deficits (Gerdtham et al. 2005). However, this is not only of financial problems.. With a relatively small size of the population in the working ages, finding the workers to provide health care for the elderly may be difficult as well.

\footnotetext{
${ }^{5}$ The idea would make more sense from a health care perspective: several people may each contribute an amount to finance extremely expensive life-saving treatment for one person, and the value of staying alive for that person may far exceed the sum of the others' utility reductions.

${ }^{6}$ There are large differences between countries. For example, while the old-age dependency ratio is currently relatively low in Eastern Europe, it will be higher than elsewhere in Europe in 2060, according to a projection recently carried out by Eurostat (2008). This reflects a combination of low fertility and little immigration. Germany and the countries in Southern Europe, currently having the highest old-age dependency ratio in Europe after a long period with low fertility, are projected to follow a step behind. Eastern Europe is also more likely than other parts of Europe to experience a decline in the total population size over the next half century, while substantial growth is projected for the north and west.

${ }^{7}$ If fertility in a country is constant and below the reproduction level, and if we assume that there is constant mortality and no international migration, the age structure of the population will eventually stabilize, but the population will continue to shrink
} 
Another argument is that ageing may have consequences for the welfare system. On the one hand, the young segments of the population may want to downsize the welfare state, given the increasing challenges involved in supporting the old population. On the other hand, there will be a larger proportion of old voters, who may want to maintain the current system or at least the parts of it that they benefit from. Thus, it is not obvious how ageing will affect the total size of the government spending (Galasso and Profeta 2007; Sanz and Velázquez 2007).

Yet another issue is that the productivity of the work force may be affected by ageing. One possible negative effect is that a higher average age of the workers itself may reduce productivity, though there is much uncertainty about this effect since there will likely be self-regulating mechanisms involving for example the use of adult educational programs (Tang and MacLeod 2006; Skirbekk 2008; Disney 1996). Second, a larger proportion of elderly may reduce the productivity of the work force through a lower savings rate, possibly compensated to some extent by more import of capital (Demery and Duck 2006). However, there may also be counteracting positive effects of the low fertility that goes hand in hand with ageing: if the total allocations to education are fixed, fewer children means larger educational investments per child, which will increase labour force productivity later. Under certain conditions, this effect may more than outweigh the costs of supporting more elderly, leaving an economic impact of low fertility and ageing that on the whole is positive (Lee and Mason 2010).

Finally, ageing may have environmental effects. Most importantly perhaps, it has been argued that old people's consumption may be less damaging to the environment than that of the younger (McDonald et al. 2006).

The importance of a possibly smaller total population size following in the wake of low fertility has been much less analysed, perhaps partly because there are still few countries that have actually experienced a population reduction. One possible issue is that a country may have smaller military power and less international political influence if the population, and therefore the absolute size of the economy, is smaller. This "nationalistic" argument is an old one, and motivated for example the early French pronatalist policies, but it may still have some relevance (Demeny 2003; Grebenik 1989, Jackson and Howe 2008). Another possibly harmful effect, relevant for some countries, is that further reduction in the population size may make it difficult for some sparsely populated regions to survive because there are fewer people to share the expenses for infrastructure (Felmingham et al. 2002). (An argument about populous countries having an advantage more generally through efficiencies of scale may be of less relevance in a globalized economy.) Further, it is possible that a reduced size of the domestic market undermines some of the optimism and willingness to take risks that one otherwise would have seen (Jackson and Howe 2008). On the positive side, a lower savings rate is needed to maintain the capital-labour ratio when the absolute size of the work force 
shrinks. In addition, a smaller population may cause less environmental damage. A trivial version of this argument is that, if all types of environmental imprints from each individual are fixed, fewer people means, for example, less emission of climate gases, less air pollution in general, less waste production, less deforestation, and less soil degradation due to food production (McNeill 2006). Reality is of course more complex because changes in population size may lead to changes in income-generating and leisure activities, in technology, and in policy, with implications for how each individual influences the environment. For example, should population decline lead to a higher average income, one may possibly - under certain conditions - experience an increased pressure on the environment. Currently, environmental concerns are reckoned among the strongest arguments against high population growth in poor countries (Cleland et al. 2006), so it may be somewhat hypocritical not to welcome a population decline in the rich part of the world (assuming that this is environmentally beneficial), and especially since the population-environment link is conditional on a number of economic and political factors (e.g. Panayoutou 1994) and may well be particularly strong overall (with some variation depending on what kind of degradation we have in mind) in affluent settings.

Another type of externality also deserves to be mentioned: A couple's fertility has effects on their own lives, and although many of the effects that are known to the couple may also be considered by themselves as positive (otherwise they might have chosen differently), they probably do not take into account in their decision-making that these effects on their own lives may have negative implications for others. In addition, there may be unforeseen effects that affect other people in a harmful way. For example, those with few children may be less integrated in the community, which may be acceptable to them (to the extent that it is foreseen), but there may be less positive implications of this for other people, one reason being the possible health effect of social cohesion (Islam et al. 2006). Another individual-level effect of low fertility is that the mothers will be more likely to have paid work. This will probably have important, and perhaps largely positive, societal implications. A related type of spillover effect would be, for example, that the entire society may be influenced if it is the case that only children tend to be less sociable than other children.

Finally, it should be noted that there is a link between the micro and the macro perspective. According to the former, women or men who have few children may suffer from that themselves. However, their own low fertility may contribute to or be partly a result of others' low fertility through learning and imitation effects (Goldstein et al. 2003; Montgomery and Casterline 1996), and they may suffer from others' low fertility as well. In other words, the parents' own well-being may be influenced by other people's fertility and their own fertility, the latter operating in part through the former or vice versa. 
As with the individual-level effect, better data and methods can help us identify such macro-level consequences of low fertility and of the resulting ageing and low population growth or even decline. It is obviously necessary to take into account when doing such work that some of the factors behind the population structure may also affect the economic and social development through other channels. In other words, one motive for continued efforts to gain further insight into the fertility determinants is that this may help us learn more about the macro-level effects.

\subsection{Should anything be done to increase fertility?}

Even if negative externalities of low fertility are identified, political interventions are not necessarily justified. Below, I discuss reasons why politicians might want to make attempts to increase fertility, and whether knowledge about fertility trends and differentials may help them make a decision on this issue. Other possible responses to the societal-level consequences of low fertility are addressed in the subsequent section.

Let us start with a simple example related to subsidies of childbearing costs. Assume that there are a number of couples who have only one child each because they think this is to their advantage (and it is not important now whether they are right about that or not). They may think that a child is only worth $€ 100,000$, while the cost of raising the child would be $€ 150,000$ Let us also assume that, for the others in society, there is a total advantage of $€ 70,000$ per additional child born. In that case, these other people would be able to offer the potential child-bearers, say, $€ 60,000$ if they have a second child. Many would accept that, since they would get a child of value $€ 100,000$ for the price of $€ 90,000$. For each couple accepting the offer, the others would earn a total of $€ 10,000$, as they pay $€ 60,000$ and the benefit is $€ 70,000$. Thus, both parties would be better off (i.e. the situation was not Pareto optimal at the outset). ${ }^{8}$

The situation would be entirely different if the advantage for the other people than the childbearing couples had been only $€ 40,000$ for each additional child born. In that case, they would not be able to "bribe" the couples to have a second child. They would need $€ 50,000$ or more each, and the others would not be willing to pay that, because it would not be in their own interest. In fact, they would lose $€ 10,000$ on such a

\footnotetext{
${ }^{8}$ This argumentation is greatly simplified. For example, the consequences of low fertility may not be felt within the life-time of the older people, who might therefore be unwilling to contribute to their solution, while others who might be interested in compensating for a different behaviour are not born yet. Further, one may criticize the very idea of maximizing average utility (indicated here, for simplicity, by money amounts) for those alive. Also other ethical principles might have been applied. For example, one might have focused on total utility, to which a new life would add regardless of how miserable it were (Blackerby et al. 2005). Another and less challenging issue is that an amount of $€ 10,000$ would mean much more for a poor than a rich person. Taking that into account would require only a fairly trivial modification of the arguments.
} 
transaction. Therefore, and in contrast to the first-mentioned case, a subsidy is not justified.

Let us now turn to the possibility of increasing the incomes of the potential parents, rather than reducing the costs of childbearing. Assume for example that a child is worth $€ 110,000$ to a couple and costs $€ 100,000$, but that they can only afford to pay $€ 50,000$. If their incomes are increased by $€ 50,000$, there is a chance that they may have a child (unless higher incomes also increase the price of the child or the parents decide to spend on something else). Anyway, they may be considered to enjoy a welfare gain of at least $€ 50,000$. If half of them have a child and half do not, and if the advantage for those who are not potential child-bearers is, say, €20,000 for each child born, one may consider taxing the latter an amount of $€ 50,000$ per potentially childbearing couple to increase the total level of well-being in society. Such a step would increase the welfare of the potential child-bearers by $€ 50,000$, but only reduce the others' welfare by $€ 50,000$ minus half of $€ 20,000$ (i.e. satisfying the Kaldor-Hicks criterion for efficient allocation; e.g. Feldman and Serrano 2006).

Rather than thinking about this in terms of taxation, we might consider the authorities as having two options if there suddenly is some money to be paid out (for example as a result of smart investments the government has made abroad): pay $€ 50,000$ to a couple at a childbearing age or $€ 50,000$ to another couple. Both parties will want the money, but the total welfare may be higher if it is given to the former.

On the other hand, if the externality effect is more than $€ 100,000$, it would be an advantage for everyone if the money is given to the potential child-bearers. The remaining population would actually be better off that way than if they got or kept the money themselves.

More generally, relevant pro-natalist policies may involve a number of benefits for the potential child-bearers (McDonald 2006). Consider, for example, an expansion of high-quality inexpensive day care centres. Parents who have a child in day care may find that this makes life easier for them, which we may consider as corresponding to an income increase. In addition, these parents as well as other couples who consider the possibility of having more children may expect that the costs of subsequent childbearing will be relatively low - provided that the supply of day care remains at the same level - and some may decide to have another child. Indeed, such fertilitystimulating effects on fertility have been documented in recent studies (Rindfuss et al. 2007). Depending on its price, its exact influence on fertility, and the societal effect of a larger number of children, an expansion of day care may leave everyone better off, the two parties better off in total (most typically, an advantage for the child-bearers that exceeds the disadvantage for the remaining population), or it may reduce the total wellbeing in society. In reality, there will always be uncertainty about this (and similarly for other policies one might consider). In addition, the issue is further complicated by the 
fact that there may also be externalities associated with letting the remaining population keep the money and with the parents' lifestyle beyond the additional childbearing, and there may be other types of effects of having children in day care, for example on their intellectual development, with consequences both for the children themselves and others. However, more knowledge about determinants of fertility, and especially about how various education, family and labour-market policies have affected fertility in the past, at least facilitates assessment of the costs of raising the number of children through various measures. This in turn increases the chance that a wise decision is taken about whether a pro-natalist policy is warranted and, if so, which factors it should include. $^{9}$

\subsection{Other responses to possible societal-level consequences}

Regardless of whether it is concluded that something should be done to increase fertility, politicians may want to make attempts to minimize the negative macro-level consequences of low fertility. Again, demographers' insight into fertility trends and determinants may be useful. This is explained below.

In particular, there are some steps that can be taken to ameliorate the consequences of ageing. One may, for example, increase the age at which workers become eligible for retirement pension, which may involve some efforts to increase the productivity of older workers (who tend to be healthier than ever before) through human capital or other investments. One may also make it easier for women to work, one may get people ready for work at a lower age through more efficient educational programs, and (unless immigration is suspected to produce major social problems) one may allow more immigration $^{10}$ (Grant et al. 2004; Blake and Mayhew 2006). The negative effect of the productivity of the work force because of ageing (even without any increase in retirement age) might be partly counteracted by life-long learning programs. In principle, it would of course also help if one could manage to get more out of the money in the health care, but this is not a sector where it is easy to make large efficiency gains. Obviously, the possible responses to ageing vary between countries

\footnotetext{
${ }^{9}$ It should be noted that such a policy must not necessarily build exclusively on economic incentives, such as mentioned above. For example, it is also possible that some people will change behaviour without economic compensation if they are informed about the externality. The good feeling of doing something for society may add to the value of a child and make them more inclined to have another one.

${ }^{10}$ As pointed out by several observers (Coleman 2008) and illustrated in a projection from the United Nations (2001), immigration is not necessarily an efficient remedy against ageing. The impact that immigrants leave on the age structure depends of course on their age, whether they give birth to many children, whether they or their descendants stimulate later immigration of young adults (especially through marriage with persons from the country of origin), and whether they return to their home country of origin when they get old.
} 
and depend, for example, on the characteristics of the labour force at the outset, the economic resources, and the political attitudes.

If the size and age structure of the future population were known, it would be easier to establish sound and appropriately scaled coping strategies such as mentioned in due time. In reality, all a planner or politician can hope for is a forecast showing possible developments of the future population structure, perhaps coupled with some indications about how likely each of them are. Most commonly, forecasters present a few discrete trajectories to illustrate the magnitude of the uncertainty, without being specific about the probability distribution, though one trajectory may be pointed to as the most likely. Obviously, the extreme trajectories cannot be considered as the lower and upper bound of what one might possibly experience in the future (i.e. there is not a $100 \%$ probability that reality falls within these trajectories). A stochastic population projection is an alternative and increasingly popular approach (see for example Booth (2006) for a review of population projection methods.) It provides information about the probability that the population measure under study falls within certain limits. For example, a $60 \%$ or a $80 \%$ confidence interval may be presented, the latter of course being wider than the former. It is not obvious what type of confidence intervals that would be most helpful to a planner: $80 \%$ intervals may be important for some purposes, and smaller intervals for others.

Regardless of whether a national forecast is deterministic or stochastic, it is based on some ideas about or models for the range of possible fertility levels in the future, and similarly for mortality and international migration. These ideas or models typically reflect the fertility history of the country. For example, a main trajectory of fertility rates may be chosen on the basis of a more or less formal extrapolation of the recent overall trend. Alternative trajectories may reflect earlier particularly low or high levels, or a confidence interval may be determined by a statistical model that essentially incorporates earlier levels of fertility and the magnitude of the annual changes that have occurred. In addition, one may have an eye to earlier forecast errors when defining possible deviations from the main fertility alternative. Further, one may draw on experts' opinions when doing this, or when making assumptions about the main alternative. These opinions will be based on the experts' knowledge about determinants of fertility and their ideas about the future development of these determinants (perhaps inspired by what has happened in other countries).

Alternatively, one might consider making more explicit use of the knowledge about fertility determinants by including them in the projection model (see also Sanderson 1998). The value of such an approach would of course hinge on the assumption that the causal effects (determinants) that one in principle hopes to identify in a certain data material also are relevant for the setting under study and throughout the projection period. To justify the approach, it must also be easier to foresee trends in 
incomes, education, and other fertility determinants than to forecast fertility more directly. A few attempts at such forecasting have been made, but they have not been very successful (Booth 2006).

The goal is of course to make the forecasts more accurate, in the sense that there is little difference between the main forecast alternative and reality. Using the stochasticprojection terminology, we may also say that the goal is to narrow the confidence intervals (e.g. reduce the difference between the upper and lower limit of the $80 \%$ interval) and make them more correct (meaning for example that in $80 \%$ of the projections presenting $80 \%$ intervals, the outcome actually fall within the interval). This is no easy task. For example, Keilman (2008) has concluded that none of the new techniques that have been employed over the last couple of decades have mattered much for the accuracy of the forecasts, which have improved very little. However, although earlier attempts to improve the forecasts - also through a more extensive use of knowledge about fertility trends and determinants - have not proved very successful, it is not impossible that future efforts to expand this knowledge, combined with development of better techniques to implement it in forecasts, some day will pay off. Since values are more stable than many other fertility determinants, one place to start may be to develop better measures of a broad set of values among adolescents and young adults and assess their importance for later reproductive behaviour.

\subsection{Another perspective: Low fertility is unproblematic, but we need to know about it}

A more extreme version of the arguments above would be that low fertility may have harmful effects, but that these can be completely outbalanced by pulling certain strings in due time - at no costs - so that low fertility really is unproblematic. For example, one might argue that low fertility will make it more difficult to find sufficient labour for old age care in the future, but that one may import labour whenever necessary, and that this really comes with no costs. It is possible that some politicians or researchers have a completely "unconcerned" attitude like this and think that the fertility level really doesn't matter in any way, in the sense that we can cope just as well with low as with high fertility (but with different policies), as long as we know some time in advance what the level will be. As just pointed out, the latter may be easier if we have good knowledge about trends and determinants of fertility, so even from such a perspective, there would be need for research in this area. 


\section{Conclusions}

There are good reasons why demographers should continue their efforts to learn about fertility trends and determinants in low-fertility settings. One is that such knowledge may be helpful when trying to find out whether low fertility actually has the harmful societal consequences through ageing and population decline that have been suggested by some observers, and whether there are important (unforeseen) consequences for the individual families. (The fact that people perhaps are somewhat unhappy because they do not have as many children as they would have liked to have if conditions were better is less of a public concern.) In principle, researchers in other areas who see it as their goal to assess the consequences of low fertility may be able to make good use of the knowledge about trends and determinants that is produced by demographers, but it is possible that more advances will be made if demographers get more involved in the process than they currently do. At present, demographers' research priorities are rather unbalanced. There is a large stream of papers about trends and determinants and quite little attention to the consequences.

Another reason for keeping up the work on trends and determinants is that, if future analysis reveals that there probably are harmful consequences of low fertility, knowledge about trends and determinants may be used to find out whether it actually is worth trying to change people's reproductive behaviour and how that might be done. In addition, even without the intention of changing fertility, politicians may be eager to know at least how widespread the low-fertility behaviour is and will be in the future, because this may help to ameliorate its consequences. It may possibly be easier to satisfy this demand if there is more knowledge about fertility trends and determinants, and if higher priority is given to research on how this knowledge can be translated into good forecasts.

Should we ever be able to conclude that low fertility has no unforeseen adverse effects at the individual level and no harmful consequences for society, there would be much less need for research on trends and determinants. However, we will probably never get into such a position. There will always be reasons to suspect that childbearing may have some important consequences that may deserve public attention.

To summarize, the message to active researchers and funding agencies is that there is indeed important work to be done on trends and determinants of fertility in lowfertility settings, but that demographers with an expertise in this also could make good use of themselves by getting more involved in efforts to understand the consequences of low fertility and perhaps to improve forecasts. Whether research in other areas, within demography or other disciplines, is even more important is a different issue. 


\section{Acknowledgements}

The helpful comments from Wendy Sigle-Rushton, Vegard Skirbekk and two anonymous reviewers are greatly appreciated. 


\section{References}

Aassve, A., Mazzuco, S., and Mencarini, L. (2006). An empirical investigation into the effect of childbearing on economic wellbeing in Europe. Statistical Methods and Applications 15(2): 209-227. doi:10.1007/s10260-006-0020-x.

Andersson, G. (1997). The impact of children on divorce risks of Swedish women. European Journal of Population 13(2): 109-145. doi:10.1023/A:1005803001129.

Angrist, J.D. and Evans, W.N. (1998). Children and their parents' labor supply: Evidence from exogenous variation in family size. American Economic Review 88(3): 450-477.

Antonucci, T.C., Arjouch, K.J., and Janevic, M.R. (2003). The effect of social relations with children on the education-health link in men and women aged 40 and over. Social Science and Medicine 56(5): 949-960. doi:10.1016/S02779536(02)00099-0.

Bagley, S., Salmon, J., and Crawford, D. (2006) Family structure and children's television viewing and physical activity. Medicine and Science in Sports and Exercise 38(5): 910-918. doi:10.1249/01.mss.0000218132.68268.f4.

Barefoot, J.C., Grønbæk, M., Jensen, G., Schnohr, P., and Prescott, E. (2005). Social network diversity and risks of ischemic heart disease and total mortality: Findings from the Copenhagen City Heart Study. American Journal of Epidemiology 161(10): 960-967. doi:10.1093/aje/kwi128.

Becker, G. (1991). A treatise on the family, enlarged edition. Harvard: Harvard University Press.

Black, S.E., Devereux, P.J., and Salvanes, K.G. (2005). The more the merrier? The effects of family size and birth order on children's education. The Quarterly Journal of Economics 120(2): 669-700. doi:10.1162/0033553053970179.

Blackerby, C., Bossert, W., and Donaldson, D. (2005). Population issues in social choice theory, welfare economics, and ethics. Cambridge: Cambridge University Press.

Blake, D. and Mayhew, L. (2006). On the sustainability of the UK state pension system in the light of the population ageing and declining fertility. The Economic Journal 116(512): F286-F305. doi:10.1111/j.1468-0297.2006.01100.x. 
Blake, J. (1968). Are babies consumer durables?:A critique of the economic theory of reproductive motivation. Population Studies 22(1): 5-25. doi:10.2307/2173350.

Booth, H. (2006). Demographic forecasting: 1980-2005 in review. International Journal of Forecasting 22(3): 547-581. doi:10.1016/j.ijforecast.2006.04.001.

Bühler, C. (2008). On the structural value of children and its implication on intended fertility in Bulgaria. Demographic Research 18(20): 569-610. doi:10.4054/DemRes.2008.18.20.

Caldwell, J.C. (1976). Toward a restatement of demographic transition theory. Population and Development Review 2(3/4): 321-366. doi:10.2307/1971615.

Cleland, J., Bernstein, S., Ezeh, A., Faundes, A., Glasier, A., and Innis, J. (2006). Family planning: The unfinished agenda. Lancet 368(9549): 1810-1827. doi:10.1016/S0140-6736(06)69480-4.

Coleman, D. (2008). The demographic effects of international migration in Europe. Oxford Review of Economic Policy 24(3): 452-476. doi:10.1093/oxrep/grn027.

Commission of the European Communities. (2006). Demographic future of Europe from challenge to opportunity. Brussels.

Council of Europe. (1996). Children and work in Europe. Strasbourg: Council of Europe Publishing.

Demeny, P. (2003). Population policy dilemmas in Europe at the dawn of the twentyfirst century. Population and Development Review 29(1): 1-28. doi:10.1111/j.1728-4457.2003.00001.x.

Demery, D. and Duck, N.W. (2006). Demographic change and the UK savings rate. Applied Economics 38(2): 119-136. doi:10.1080/00036840500390361.

Disney, R. (1996). Can we afford to grow old? Cambridge: MIT Press.

Dormont, B., Grignon, M., and Huber, H. (2006). Health expenditure growth: Reassessing the threat of ageing. Health Economics 15(9): 947-963. doi:10.1002/hec. 1165 .

Downey, D.B. (1995). When bigger is not better: Family size, parental resources, and children's educational performance. American Sociological Review 60(5): 746761. doi:10.2307/2096320.

Downey, D.B. and Condron, D.J. (2004). Playing well with others in kindergarten: The benefit of siblings at home. Journal of Marriage and Family 66(2): 333-350. doi:10.1111/j.1741-3737.2004.00024.x. 
Easterlin, R.A. and Crimmins, E.M. (1985). The fertility revolution: A supply-demand analysis. Chicago: University of Chicago Press.

Elster, J. and Skog, O.-J. (eds.) (1999). Getting hooked: Rationality and addiction. Cambridge: Cambridge University Press.

England, P. and Folbre, N. (2005). Gender and economic sociology. In: Smelser, N.J. and Swedberg, R. (eds.). Handbook of economic sociology, second edition. Princeton: Russel Sage Foundation and Princeton University Press: 627-649.

European Foundation for the Improvement of Living and Working Conditions. (2004). Fertility and family issues in an enlarged Europe. Dublin.

Eurostat. (2008). Ageing characterises the demographic perspectives of the European societies. Statistics in Focus 72/2008.

Evenson, R.J. and Simon, R.W. (2005) Clarifying the relationship between parenthood and depression. Journal of Health and Social Behavior 46(4): 341-358. doi:10.1177/002214650504600403.

Feldman, A.M. and Serrano, R. (2006). Welfare economics and social choice theory, second edition. Heidelberg: Springer.

Felmingham, B., Jackson, N., and Zhang, Q. (2002). Indicative impacts of population decline on the operations of local government in Tasmania. Australasian Journal of Regional Studies 8: 95-109.

Fletcher, B., Gulanick, M., and Lamendola, C. (2002). Risk factors for type 2 diabetes mellitus. Journal of Cardiovascular Nursing 16(2): 17-23.

Galasso, V. and Profeta, P. (2007). How does ageing affect the welfare state? European Journal of Political Economy 23(2): 554-563. doi:10.1016/j.ejpoleco.2006.04.001.

Gerdtham, U.-G., Lundin, D., and Sáez-Marti, M. (2005). The ageing of society, health service provision, and taxes. Journal of Population Economics 18(3): 519-537. doi:10.1007/s00148-005-0223-8.

Goldstein, J., Lutz, W., and Testa, M.R. (2003). The emergence of sub-replacement family size ideals in Europe. Population Research and Policy Review 22(5-6): 479-496. doi:10.1023/B:POPU.0000020962.80895.4a.

Grant, J., Hoorens, S., Sivadasan, S., van het Loo, M., DaVanzo, J., Hale, L., Gibson, S., and Butz, W. (2004). Low fertility and population ageing. Causes, consequences and policy options. Prepared for the European commission. Santa 
Monica, CA: RAND Corporation. (MG-206-EC). http://www.rand.org/pubs/monographs/2004/RAND_MG206.pdf.

Grebenik, E. (1989). Demography, democracy, and demonology. Population and Development Review 15(1): 1-22. doi:10.2307/1973403.

Grundy, E. and Kravdal, Ø. (2008). Reproductive history and mortality in late middle age among Norwegian men and women. American Journal of Epidemiology 167(3): 271-279. doi:10.1093/aje/kwm295.

Hobcraft, J. (2006). The ABC of demographic behaviour: How the interplays of alleles, brains, and context over the life course should shape research aimed at understanding population processes. Population Studies 60(2): 153-187. doi:10.1080/00324720600646410.

Hoffman, L.W. and Manis, J.D. (1979). The value of children in the United States: A new approach to the study of fertility. Journal of Marriage and the Family 41(3): 583-596. doi:10.2307/351628.

Hoffman, L.W. and Manis, J.D. (1982). The value of children in the United States. In: Nye, F.I. (ed.). Family relationships: Rewards and costs. Beverly Hills, CA: Sage Publications: 143-170.

Islam, M.K., Merlo, J., Kawachi, I., Lindström, M., and Gerdtham, U.-G. (2006). Social capital and health: Does egalitarianism matter? A literature review. International Journal of Equity in Health 5: 3. doi:10.1186/1475-9276-5-3.

Jackson, R. and Howe, N. (2008). The graying of the great powers. Demography and geopolitics in the $21^{\text {st }}$ century. Washington: Center for Strategic and International Studies.

Joshi, H. (2002). Production, reproduction, and education: Women, children, and work in a British perspective. Population and Development Review 28(3): 445-474. doi:10.1111/j.1728-4457.2002.00445.x.

Keilman, N.W. (2008). European demographic forecasts have not become more accurate during the past 25 years. Population and Development Review 34(1): 137-153. doi:10.1111/j.1728-4457.2008.00209.x.

Keister, L.A. (2003). Sharing the wealth: The effect of siblings on adults' wealth ownership. Demography 40(3): 521-542.

Kendig, H., Dykstra, P.A., van Gaalen, R.I., and Melkas, T. (2007). Health of aging parents and childless individuals. Journal of Family Issues 28(11): 1457-1486. doi:10.1177/0192513X07303896. 
Knoester, C. and Eggebeen, D.J. (2006). The effects of the transition to parenthood and subsequent children on men's well-being and social participation. Journal of Family Issues 27(11): 1532-1560. doi:10.1177/0192513X06290802.

Kohler, H.-P., Behrman, J.R., and Skytthe, A. (2005). Partner + children = happiness? The effects of partnerships and fertility on well-being. Population and Development Review 31(3): 407-445. doi:10.1111/j.1728-4457.2005.00078.x.

Kravdal, Ø. and Rindfuss, R.R. (2008). Changing relationships between education and fertility: A study of women and men born 1940-1964. American Sociological Review 73(5): 854-873. doi:10.1177/000312240807300508.

Kulu, H., Vikat, A., and Andersson, G. (2007). Settlement size and fertility in the Nordic countries. Population Studies 61(3): 265-285. doi:10.1080/0032472 0701571749 .

Lee, R. and Mason, A. (2010). Fertility, human capital, and economic growth over the demographic transition. Forthcoming in European Journal of Population. doi:10.1007/s10680-009-9186-X.

Lesthaeghe, R. and Surkyn, J. (1988). Cultural dynamics and economic theories of fertility change. Population and Development Review 14(1): 1-45. doi:10.2307/1972499.

Li, H., Zhang, J., and Zhu, Y. (2008). The quantity-quality trade-off of children in a developing country: Identification using Chinese twins. Demography 45(1): 223243. doi:10.1353/dem.2008.0006.

Lusyne, P. and Page, H. (2008). The impact of children on a parent's risk of suicide following death of a spouse, Belgium 1991-96. Population Studies 62(1): 55-67. doi:10.1080/00324720701788566.

Lutz, W. (2007). Adaptation versus mitigation policies on demographic change in Europe. Vienna Yearbook of Population Research 2007: 19-25. doi:10.1553/populationyearbook2007s19.

Lutz, W. and Skirbekk,V. (2005). Policies addressing the tempo effect in low-fertility countries. Population and Development Review 31(4): 699-720. doi:10.1111/j.1728-4457.2005.00094.x.

Mastekaasa, A. (2000). Parenthood, gender and sickness absence. Social Science and Medicine 50(12): 1827-1842. doi:10.1016/S0277-9536(99)00420-7. 
McDonald, P. (2006). Low fertility and the state: The efficacy of policy. Population and Development Review 32(3): 485-510. doi:10.1111/j.17284457.2006.00134.x.

McDonald, G.W., Forgie, V.E., and MacGregor, C. (2006). Treading lightly: Ecofootprints of New Zealand's ageing population. Ecological Economics 56(3): 424-439. doi:10.1016/j.ecolecon.2005.09.019.

McIntosh, C.A. and Finkle, J.L. (1995). The Cairo conference on population and development. A new paradigm? Population and Development Review 21(2): 223-260. doi:10.2307/2137493.

McNeill, J.R. (2006). Population and the natural environment: Trends and challenges. Population and Development 32(suppl): 183-201.

Mirowski, J. (2005). Age at first birth, health, and mortality. Journal of Health and Social Behaviour 46(1): 32-50. doi:10.1177/002214650504600104.

Montgomery, M.R. and Casterline, J.B. (1996). Social learning, social influence, and new models of fertility. Population and Development Review 22(suppl): 151175. doi: $10.2307 / 2808010$.

Murphy, M. and Knudsen, L.B. (2002). The intergenerational transmission of fertility in contemporary Denmark: The effects of number of siblings (full and half), birth order, and whether male or female. Population Studies 56(3): 235-248. doi:10.1080/00324720215937.

Musick, K. and Mare, R.D. (2004). Family structure, intergenerational mobility, and the reproduction of poverty: Evidence for increasing polarization? Demography 41(4): 629-648. doi:10.1353/dem.2004.0034.

Nauck, B. and Klaus, D. (2007). The varying value of children: Empirical results from eleven societies in Asia, Africa and Europe. Current Sociology 55(4): 487-503. doi:10.1177/0011392107077634.

OECD (2002). Women at work. Who are they and how are they faring? (Chapter 2) In: Employment outlook 2002. Paris: Organisation for Economic Co-operation and Development.

Palen, J.J. (1986). Fertility and eugenics. Singapore's population policies. Population Research and Policy Review 5(1): 3-14. doi:10.1007/BF00124875.

Panayoutou, T. (1994). Population, environment, and development nexus. In: Cassen, R. (ed.). Population and development: Old debates, new conclusions. New Brunswick: Transaction Publishers: 149-180. 
Polit, D.F. and Falbo, T. (1988). The intellectual achievement of only children. Journal of Biosocial Science 20(3): 275-285. doi:10.1017/S0021932000006611.

Rendall, M.S. and Bahchieva, R.A. (1998). An old-age security motive for fertility in the United States. Population and Development Review 24(2): 293-307. doi:10.2307/2807975.

Rijken, A.J. and Liefbroer, A.C. (2009). The influence of partner relationship quality on fertility. European Journal of Population 25(1): 27-44. doi:10.1007/s10680-0089156-8.

Rindfuss, R.R., Guilkey, D., Morgan, S.P., Kravdal, Ø., and Guzzo, B.K. (2007). Child care availability and first birth timing in Norway. Demography 44(2): 345-372. doi:10.1353/dem.2007.0017.

Russo, I.H. and Russo, J. (2007). Primary prevention of breast cancer by hormoneinduced differentiation. Recent Results in Cancer Research 174: 111-130. doi:10.1007/978-3-540-37696-5_11.

Salehi, F., Dunfield, L., Philips, K.P., Krewski, D., and Vanderhyden, B.C. (2008). Risk factors for ovarian cancer: An overview with emphasis on hormonal factors. Journal of Toxicology and Environmetal Health, Part B: Critical Reviews 11(3-4): 301-321. doi:10.1080/10937400701876095.

Sanderson, W.C. (1998). Knowledge can improve forecasts: A review of selected socioeconomic population projection models. Population and Development Review 24(suppl): 88-117. doi:10.2307/2808052.

Sanz, I. and Velázquez, F.J. (2007). The role of ageing in the growth of government and social welfare spending in the OECD. European Journal of Political Economy 23(4): 917-931. doi:10.1016/j.ejpoleco.2007.01.003.

Skilton, M.R., Sérusclat, A., Begg, L.M., Moulin, P., and Bonnet, F. (2009). Parity and carotid atherosclerosis in men and women: Insights into the roles of childbearing and child-rearing. Stroke 40(4): 1152-1157. doi:10.1161/STROKEAHA. 108.535807 .

Skirbekk, V. (2008). Age and productivity capacity: Descriptions, causes and policy options. Ageing Horizons 8: 4-12.

Steele, F., Sigle-Rushton, W., and Kravdal, Ø. (2009). Consequences of family disruption on children's educational outcomes in Norway. Demography 46(3): 553-574. doi:10.1353/dem.0.0063. 
Tang, J. and MacLeod, C. (2006). Labour force ageing and productivity performance in Canada. Canadian Journal of Economics 39(2): 582-603. doi:10.1111/j.00084085.2006.00361.x.

Testa, M.R. (2007). Childbearing preferences and family issues in Europe: Evidence from the Eurobarometer 2006 survey. Vienna Yearbook of Population Research 2007: 357-379. doi:10.1553/populationyearbook2007s357.

Twenge, J.M., Campbell, W.K., and Foster, C.A. (2003). Parenthood and marital satisfaction: A meta-analytic review. Journal of Marriage and Family 65(3): 574-583. doi:10.1111/j.1741-3737.2003.00574.x.

United Nations. (2001). Replacement migration: is it a solution to declining and ageing populations? Population Division. Department of Economic and Social Affairs.

Wang, X.T., Kruger, D.J., and Wilke, A. (2009). Life history variables and risk-taking propensity. Evolution and Human Behaviour 30(2): 77-84. doi:10.1016/j.evolhumbehav.2008.09.006.

Zhang, G. and Zhao, Z. (2006). Reexamining China's fertility puzzle: Data collection and quality over the last two decades. Population and Development Review 32(2): 293-321. doi:10.1111/j.1728-4457.2006.00119.x. 
Kravdal: Demographers' interest in fertility trends and determinants in developed countries

\section{Appendix}

\section{Table A1: Classification ${ }^{\text {a }}$ of papers on fertility and its consequences in contemporary developed countries, published in five major general demography journals}

\begin{tabular}{|c|c|c|c|c|c|}
\hline & Demography & $\begin{array}{l}\text { Population } \\
\text { Studies }\end{array}$ & $\begin{array}{l}\text { Population and } \\
\text { Development } \\
\text { Review }\end{array}$ & $\begin{array}{l}\text { European } \\
\text { Journal of } \\
\text { Population }\end{array}$ & $\begin{array}{l}\text { Demographic } \\
\text { Research }^{\star *}\end{array}$ \\
\hline & $1990-2007$ & $1990-2007$ & $1990-2007^{*}$ & $1990-2007$ & $1999-2007$ \\
\hline Fertility trends, measurement, determinants ${ }^{b}$ & 49 & 32 & 48 & 52 & 51 \\
\hline Consequences of fertility for women's work & 10 & 2 & 3 & 12 & 0 \\
\hline Consequences of fertility for family behaviour ${ }^{c}$ & 4 & 1 & 0 & 3 & 0 \\
\hline Other individual-level consequences of fertility ${ }^{d}$ & 5 & 2 & 4 & 2 & 1 \\
\hline \multicolumn{6}{|l|}{ Consequences of or description of ageing or } \\
\hline population decline/growth & 8 & 0 & 19 & 9 & 1 \\
\hline Consequences of age at first birth in particular & 1 & 0 & 1 & 1 & 0 \\
\hline Compensating for low fertility/ageing & 2 & 1 & 1 & 3 & 0 \\
\hline Forecasts of fertility & 0 & 1 & 2 & 2 & 0 \\
\hline \multicolumn{6}{|l|}{$\begin{array}{l}\text { Papers that neither deal specifically with } \\
\text { developed countries nor with developing } \\
\text { countries, but that are more general: }\end{array}$} \\
\hline Fertility measurements, determinants, theory & 9 & 9 & 13 & 0 & 6 \\
\hline Individual-level consequences & 1 & 0 & 0 & 1 & 0 \\
\hline Consequences of population changes & 2 & 1 & 38 & 3 & 0 \\
\hline $\begin{array}{l}\text { Forecasts, mathematical demography, changes } \\
\text { in population structure }\end{array}$ & 6 & 4 & 14 & 4 & 9 \\
\hline
\end{tabular}

*including supplements

${ }^{* *}$ excluding supplements

${ }^{a}$ Classification is difficult, especially because topics are hard to define sharply and because some papers address multiple topics. However, few papers place much emphasis on both consequences and determinants of fertility.

${ }^{\mathrm{b}}$ Papers on pro-natalist policies are included, but not those on abortion and those having a strict focus on whether the child is born in wedlock

${ }^{c}$ Only papers with a rather explicit focus on effects of fertility are included.

${ }^{\mathrm{d}}$ Papers dealing with consequences of whether the child is wanted or not are excluded. 